\title{
Measurement and evaluation of whole-body vibrations
}

\author{
M. Uchikune
}

Department of Precision Machinery Engineering, College of Science \& Technology, Nihon University, Japan.

\begin{abstract}
A study was made to find the physiological and the psychological effects of whole-body vibration in a very low frequency range and an experiment was carried out using multi-input vibration testing equipment. Physiological effects were examined by investigating the effects on the cardiovascular system, respiratory movement and salivation to confirm the effects on the autonomic nervous system. It is necessary to have data for those subjected to vibration and the aims were to serve as a cautionary guide for the application of frequencyweighting curves with respect to health. Exposure to $21-\mathrm{min}$, equivalent acceleration equal to or greater than $0.11 \mathrm{~m} / \mathrm{s}^{2}$ r.m.s. is considered the state of sympathetic nervous system.

The health effect range appeared to the acceleration, frequency, direction and duration (21-min).

These effects require very low frequencies for long duration exposures. It made a physiological comparison between the Standard and these results. The guide for the applications in health that would results from sitting on a seat surface can be evaluated using the frequency-weightings in the appropriate standard and the acceleration can be calculated from the frequency-weightings.
\end{abstract}

\section{Introduction}

In this paper, the purpose is to make the physiological and psychological effect of those subjected to the vibration clear and the aim is to make a cautionary 


\section{Environmental Health Risk}

guide for the application of frequency-weighting curves with respect to health. The standard is not well defined on the effects.

Concerning short term exposure, the risk is caused as a result of the wholebody vibrations.

The vibration dose values at which various degrees of adverse comment may be expected in buildings based on International Standard 2631.

The effects of vibration in buildings for workers are based on psychological evaluation and the workers must receive the risk of exposure to whole-body vibration, and subjects are measured for the physiological effects for that purpose. In the work place, there are several possible adverse comments, so the values of the acceleration are shown with on the Critical working areas in the acceleration of $0.2 \mathrm{~m} / \mathrm{s}^{2}$, residential in $0.4-0.8 \mathrm{~m} / \mathrm{s}^{2}$, office in $0.8 \mathrm{~m} / \mathrm{s}^{2}$, and workshops in $1.6 \mathrm{~m} / \mathrm{s}^{2}$. In traffic systems, the public bus (large-sized car, smallsized car) was decided on acceleration from 0.18 to $0.60 \mathrm{~m} / \mathrm{s}^{2}$ and the crane and the container of docks were decided on from 0.21 to $0.60 \mathrm{~m} / \mathrm{s}^{2}$ with operators.

This dose values in the above acceleration are applicable irrespective of age and gender, and moreover, the whole-body vibration occurs as a continuous vibration.

It was necessary that the composition of a Standard for whole-body vibration, including the health effects of vibration on the autonomic nervous system, were studied in this paper.

\section{Method}

This study was performed using multi-input vibration testing equipment in the large structure testing building at this faculty. The university students were used as the subjects, all were in good health and of both genders.

The subjects sat with their legs down in the seated position on the vibration table and covered their ears with earmuffs. In this vibrating condition they were examined from $0.01 \mathrm{~Hz}$ to $0.8 \mathrm{~Hz}$ with whole-body vibration. Such a vibration frequency is an everyday occurrence in a workshop and an occupational disease occurs after working hours on it. The amplitudes of the vibration table were 15 , $25,50,100,125,150,175$ and $200 \mathrm{~mm}$. The accelerations of vibration ranged over $0.000070-0.78 \mathrm{~m} / \mathrm{s}^{2}$. These accelerations examined the range, including the low probability of adverse comment in Standard.

The examination used was the triangular wave and the sinusoidal wave for $\mathrm{x}$-axis (for-and-aft) and $\mathrm{y}$-axis (lateral) during 15, 21-min. These made the waveforms by this multi-input vibration testing equipment.

Physiological effects were examined by change on the cardiovascular system, respiratory movement, skin temperature, and salivation. In our previous experiment of seated subjects was found the physiological change that we did before, and this state acted on the sympathetic and the para-sympathetic nervous system.

There is a need to find the threshold level, the direction, and the exposure time in the working place. The sensor of measurement used was the thermistor, 
bio-amp., thermometer, balance test meter, and $\mathrm{pH}$ meter. The outputs were replaced from the amp to be recorded onto a recorder.

The amount of saliva secretion was measured at intervals of 3-minutes by inserting a dental cotton roll under the tongue. The heart-rate ratio and respiratory frequency were expressed as a ratio of each measured value to the reference values of the said elements with 30 seconds as a criterion value prior to vibrating (baseline value). As for the measuring time in the cases of heart-rate ratio and respiratory frequency, a series of measurement were performed for 30 seconds at intervals of 3-minutes.

An introspective method, with which the feelings aroused in a subject's mind were described as one of the suitable items in an evaluation paper after the experiment. In accordance with a semantic differential method, the adequate terms for the low frequencies were chosen with respect to the 7-grade evaluation.

The evaluation points were given as shown below. Psychological evaluation by the introspective method of numerical values showed that six (item of comfortable level) and seven grades were converted to a scale numbered 7 in which, "4" represented "normal". These grades were selected according to the twenty items. The words were as follows: unpretentious, amusing, smooth, friendly, calm, sharp, active, violent, favorite, variable, fresh, strong, heavy, hard, security, speedy, aggressive, tired, unpleasant, great.

These words were based on our previous study and it was found that a suitable word for this vibration was among them.

\section{Results and conclusions}

The opposite action of autonomic nervous system functioned to keep at a constant the human body, so the function of heart rate and respiratory rate increased on the state of sympathetic nervous system and restrained on the parasympathetic nervous system. The decreasing of the salivation is caused by sympathetic nervous system. That effects by the acceleration and the frequency of the head, which are to be transmitted to the human body. The increase is caused by the state of para-sympathetic nervous system. The physiological indicator showed the ratio as follows. The measured value of each divided by the before exposure to vibration was shown as the ratio. The figure gives analytical results brought about from the observation referred to above.

Figure 1 shows the state of the sympathetic nervous system with sinusoidal wave for $\mathrm{x}$-axis (for-and-aft) and the acceleration of the seat surface was at 0.11 , $0.17,0.22,0.38,0.45$, and $0.56 \mathrm{~m} / \mathrm{s}^{2}$ r.m.s.. These results calculated the heart rate, respiratory rate, and saliva secretion during 21-min (male aged 21-24, female aged 18-20). On the sinusoidal wave for $\mathrm{x}$-axis (for-and-aft), the skin temperature decreased the acceleration of $0.56 \mathrm{~m} / \mathrm{s}^{2}$ r.m.s. at $3-\mathrm{min}$ and $21-\mathrm{min}$. The increase was noted in the physiological indicator by the heart-rate ratio, the respiratory rate ratio at $0.2 \mathrm{~Hz}-100 \mathrm{~mm}, 0.2 \mathrm{~Hz}-150 \mathrm{~mm}, 0.3 \mathrm{~Hz}-150 \mathrm{~mm}, 0.4$ $\mathrm{Hz}-100 \mathrm{~mm}$, and $0.4 \mathrm{~Hz}-125 \mathrm{~mm}$, whereas the amount of the saliva secretion decreased in these data and the results compared these data with the baseline 


\section{Environmental Health Risk}

value.

At the $y$-axis (lateral) in Figure 2, it was shown that the physiological effects changed the frequent occurrence during 21 -min at $0.14,0.20,0.22,0.45$, 0.56 , and $0.67 \mathrm{~m} / \mathrm{s}^{2}$ r.m.s. (male aged $21-26$, female aged $19-23$ ).

The increase was noted in the physiological indicator by the heart-rate ratio, the respiratory rate ratio at $0.2 \mathrm{~Hz}-125 \mathrm{~mm}, 0.2 \mathrm{~Hz}-175 \mathrm{~mm}, 0.4 \mathrm{~Hz}-50 \mathrm{~mm}, 0.4 \mathrm{~Hz}-$ $100 \mathrm{~mm}, 0.4 \mathrm{~Hz}-125 \mathrm{~mm}$, and $0.4 \mathrm{~Hz}-150 \mathrm{~mm}$, whereas the amount of the saliva secretion decreased in these data and the results compared these data with the baseline value.

The decrease of the $\mathrm{pH}$ ratio was noted in the vibration frequency at 0.45 $\mathrm{m} / \mathrm{s}^{2}-25 \mathrm{~mm}-0.8 \mathrm{~Hz}, 0.56 \mathrm{~m} / \mathrm{s}^{2}-125 \mathrm{~mm}-0.4 \mathrm{~Hz}, 0.67 \mathrm{~m} / \mathrm{s}^{2}-150 \mathrm{~mm}-0.4 \mathrm{~Hz}$ during 21-min. The decrease of 2.6-2.8\% band was caused in these ranges, compared these data with the baseline value, whereas in $0.0045 \mathrm{~m} / \mathrm{s}^{2}-100 \mathrm{~mm}-0.04 \mathrm{~Hz}$, $0.0067 \mathrm{~m} / \mathrm{s}^{2}-150 \mathrm{~mm}-0.04 \mathrm{~Hz}$, and $0.028 \mathrm{~m} / \mathrm{s}^{2}-100 \mathrm{~mm}-0.1 \mathrm{~Hz}$ were increased $1.2-2.7 \%$ (female).

As the impact wave, it considered the triangular wave and the guide for the application of frequency-weighting curves were shown for health weightings. It was implied that the state of value in this range was due to the transmissibility caused by the vibration frequency. The heart-rate ratios were more than one in the case of vibration with amplitudes of $25,50,100,125,150 \mathrm{~mm}$ and frequencies of $0.2,0.3,0.6 \mathrm{~Hz}$, and acceleration at $0.11,0.13,0.14,0.17,0.25$ $\mathrm{m} / \mathrm{s}^{2}$. The respiratory rate ratios tended to increase in the case of frequencies of more than $0.1 \mathrm{~Hz}$, so that $0.2,0.4$, and $0.6 \mathrm{~Hz}$, amplitudes were $25,50,100,125$, and $175 \mathrm{~mm}$, acceleration at $0.11,0.14,0.22$, and $0.25 \mathrm{~m} / \mathrm{s}^{2}$. The ratio of saliva secretion tended to decrease in the case of vibration with amplitudes of 25,50 , $100,125,150,175 \mathrm{~mm}$ and there were an experimental points at $0.13,0.14,0.22$, and $0.25 \mathrm{~m} / \mathrm{s}^{2}$.

The decrease of the $\mathrm{pH}$ ratio was noted in the vibration frequency at 0.11 $\mathrm{m} / \mathrm{s}^{2}-100 \mathrm{~mm}-0.2 \mathrm{~Hz}$, and $0.14 \mathrm{~m} / \mathrm{s}^{2}-125 \mathrm{~mm}-0.2 \mathrm{~Hz}$ during $15-\mathrm{min}$. The decrease of $2.6-4.7 \%$ band was caused in these ranges, compared these data with the baseline value (y-axis, female). At $0.13 \mathrm{~m} / \mathrm{s}^{2}-50 \mathrm{~mm}-0.3 \mathrm{~Hz}$, and $0.22 \mathrm{~m} / \mathrm{s}^{2}$ $50 \mathrm{~mm}-0.4 \mathrm{~Hz}$ during 15-min, the decrease of 1.3-2.4\% band was caused in these ranges, compared these data with the baseline value, whereas in at 0.00014 $\mathrm{m} / \mathrm{s}^{2}-50 \mathrm{~mm}-0.01 \mathrm{~Hz}, 0.0017 \mathrm{~m} / \mathrm{s}^{2}-25 \mathrm{~mm}-0.05 \mathrm{~Hz}, 0.0022 \mathrm{~m} / \mathrm{s}^{2}-50 \mathrm{~mm}-0.04 \mathrm{~Hz}$, $0.0089 \mathrm{~m} / \mathrm{s}^{2}-50 \mathrm{~mm}-0.08 \mathrm{~Hz}$, and $0.016 \mathrm{~m} / \mathrm{s}^{2}-25 \mathrm{~mm}-0.15 \mathrm{~Hz}$ were increased $1.0-$ $2.7 \%$ (y-axis, male).

The length and the area of body sway were registered with closed eyes by using the balance meter. The subjects stood on the balance meter with one leg.

The ratios of the area of body sway when the subjects' eyes were closed was shown and it tended to increase with amplitudes of $25,50,100,125,150$, $175 \mathrm{~mm}$, frequency of $0.2,0.6 \mathrm{~Hz}$, and acceleration at $0.11,0.14,0.17,0.25 \mathrm{~m} / \mathrm{s}^{2}$. The effects by these accelerations were shown the movement-area of body sway when the eyes were closed.

Psychological evaluation by the introspective method of numerical values showed that six and seven grades were converted to scale numbered $(1-6,7)$ in which "4" represented "normal". It was felt that when the acceleration was 


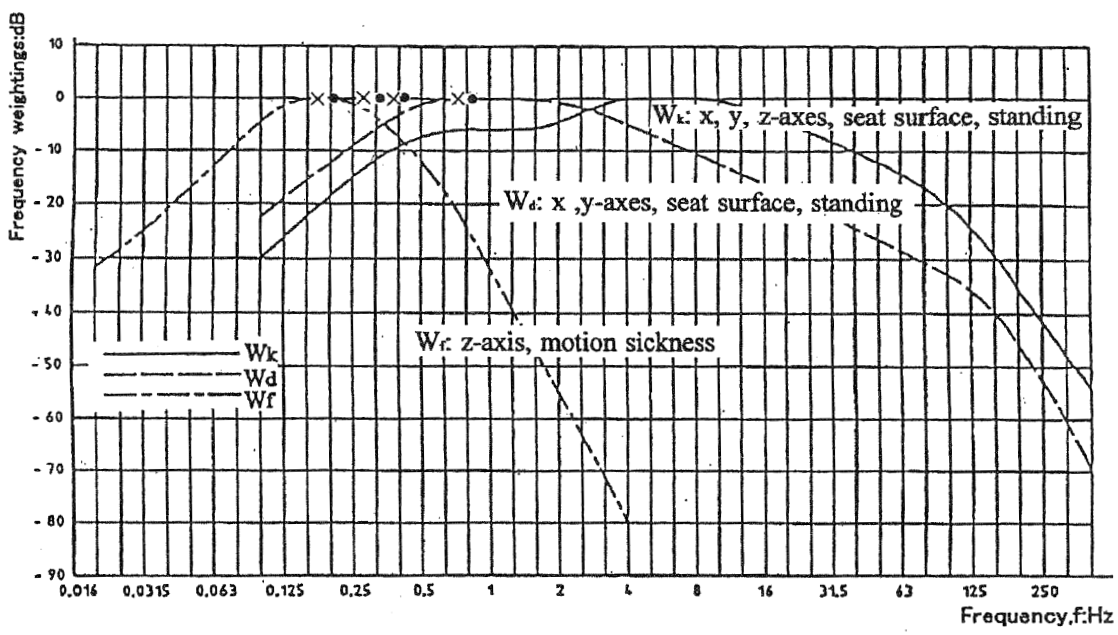

Figure 1: ISO of frequency weighting curves for principal weightings in axes. The magnitude of whole-body vibration may consider the weightings as the vibration frequency.

The state of the sympathetic nervous system with sinusoidal wave for $x$-axis, seat surface concerning the heart rate, respiratory rate, and saliva secretion during 21-min. ( $x$ :male aged 21-24, : female aged 18-20)

$\left(\right.$ Acceleration $=0.11,0.17,0.22,0.38,0.45,0.56 \mathrm{~ms}^{-2}$ r.m.s. $)$

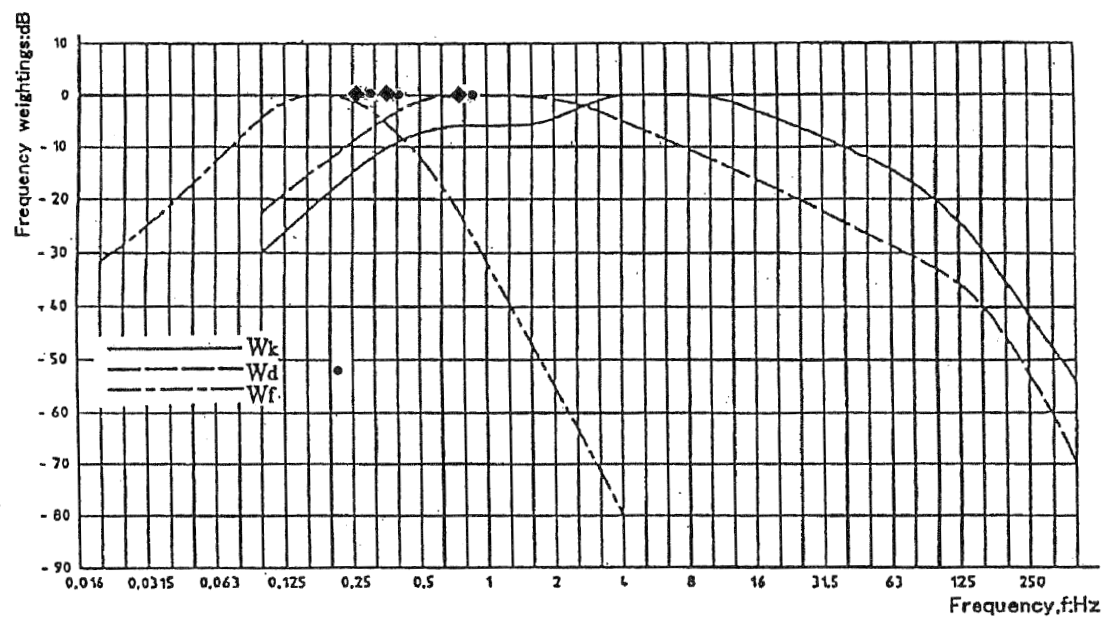

Figure 2: The state of the sympathetic nervous system with sinusoidal wave for $y$-axis, seat surface concerning the heart rate, respiratory rate, and saliva secretion during 21-min. ( : :male aged $21-26$, female aged 19-23) $\left(\right.$ Acceleration $=0.14,0.20,022,0.45,0.56,0.67 \mathrm{~ms}^{-2}$ r.m.s. $)$ 


\section{Environmental Health Risk}

"unpleasant" to exceed $0.20 \mathrm{~m} / \mathrm{s}^{2}$. On the subjects, $0.67 \mathrm{~m} / \mathrm{s}^{2}$ or $0.78 \mathrm{~m} / \mathrm{s}^{2}$ decreased to $2.6,2.8$ (level: $1-7$ ) of the evaluation value and that low frequency area which gave "normal for pleasant" in the range $0.00094-0.028 \mathrm{~m} / \mathrm{s}^{2}$. Those data were shown at frequency range from 0.015 to $0.1 \mathrm{~Hz}$. The uncomfortability tended to increase with the increasing of acceleration to exposure vibration.

Fore-and-aft vibration with a triangular wave was noted for females and the evaluation point exhibited below 4.0 (level: $1-6$ ) at $0.17 \mathrm{~m} / \mathrm{s}^{2}$. The same adjective of physiological tendency was used, "hard, great, strong, violent, sharp, aggressive, and speedy". The difference of the evaluation point, at which the wave was not the same, showed a contribution to the effects of acceleration.

The state of predominance of the sympathetic nervous system was shown at $0.11,0.14$, and $0.22 \mathrm{~m} / \mathrm{s}^{2}$ or more in 15-min and $21-\min$ (x: for-and-aft, $\mathrm{y}$ : lateral, female).

Furthermore, it showed the range of the health effects in the directions of the $x, y$-axes to the human body under the environment of this vibration area.

According to a report concerning the experiment previously conducted by us, the effects by acceleration ranging from $0.11 \mathrm{~m} / \mathrm{s}^{2}$ in horizontal direction of the frequency ranging from $0.2 \mathrm{~Hz}$. which are to be transmitted to a human body were seen.

The magnitude of whole-body vibration may consider the weighting as the vibration frequency.

Standards must be made of risk resulting from this experiment of wholebody vibrations which are affecting the physiological and psychological level.

\section{References}

[1] Dupuis H., Zerlett G., Responses of whole-body vibration. Translation: Matsumoto T., Okada A., Ariizumi M., Nohara S., \& Inaba R., Nagoya Univ.-Press, Japan, pp. 62-109, 1989.

[2] International Organization for Standardization, ISO2631 Part 1, 1997.

[3] Nakamura Y., Psychological and Social Psychology. Kosei-Press Co., Japan, 1976.

[4] Oshima M., Theory of Vibration on Human Body. Tokyo Univ.- Press, Japan, 1969.

[5] Uchikune M., Yoshida Y., Studies of the effects of low frequency vibration on the human body -Physiological and psychological effects of low frequency horizontal vibration-. Proc. of the 11th Int. Conf. On the Ergonomics Association. IEA, Paris, pp. 915-917, 1991.

[6] Uchikune M., Yoshida Y., \& Shirakawa S., Studies on the effects of low frequency horizontal vibration to the human body. Low fre. noise, vibra. \& active control, (13), pp. 139-142, 1994.

[7] Uchikune M., Shirakawa S., \& Yoshida Y., The effects of a low frequency range exposed to vibration on the whole-body. Proc. of the 25th Int. Conf. On occupational health. ICOH, Stockholm, p. 222, 1996.

[8] Uchikune M., Shirakawa S., \& Yoshida Y., Studies in physiological effect 
and psychological evaluation on a human body with the low frequency vibration. Proc. of the 13th Int. Conf. On the Ergonomics Association. IEA, Tampere, pp. 602-604, 1997.

[9] Uchikune M., Yoshida Y., The effects on exposure of the whole-body to low frequency vibration in the range $0.01 .0 .06 \mathrm{~Hz}$. Low fre. noise, vibra. \& active control, (18), pp. 77-83, 1999.

[10] Uchikune M., Shirakawa S., Studies for the evaluation of human-body exposure to whole-body vibration at very low frequencies. Proc. of the 14th Int. Conf. On the Ergonomics Association. IEA, San Diego, p. 58, 2000.

[11] Uchikune M., Health effects of feet vibration on autonomic nervous system. Proc. of the 26th Int. Conf. On Occupational Health. ICOH, Singapore, p.705, 2000.

[12] Uchikune M., Development of a vibration acceleration meter for low frequency range. The Japanese society of tech. education.(42), pp.75-81, 2000.

[13] Uchikune M., The evaluation of horizontal whole-body vibration in the low frequency range. Low fre. noise, vibra. \& active control, (21), pp. 29-36, 2002.

[14] Uchikune M., Effects on health and perception from whole-body vibration exposure. Proc. of the Third Int. Conf. On Women, Work \& Health, Stockholm, pp. 89-90, 2002.

[15] Yoshida Y. (eds), Fundamental of Human Ergonomics. Corona-Press Co., Japan, 1980. 